\title{
The influence of dissolved oxygen on growth and degradation of Cypermethrin by Pseudomonas using a biosimulator
}

\author{
S. Jilani \\ Department of Science, Textile Institute of Pakistan, Pakistan
}

\begin{abstract}
Cypermethrin, a least water soluble pesticide, was selected because such compounds are very difficult to remove from environmental systems by conventional means. In this study, Pseudomonas strain (IES-Ps-1) was used to assess its potential for Cypermethrin degradation. Continuous agitation of a wastewater sample in biosimulator was found to be suitable for growth as well as the metabolism of Cypermethrin by Pseudomonas. At optimum temperature (28$30^{\circ} \mathrm{C}$ ) using $8-9 \mathrm{mg} / \mathrm{L}$ dissolved oxygen (DO), $>85 \%$ degradation of Cypermethrin was achieved after 48 hours when the initial added concentration was $80 \mathrm{mg} / \mathrm{L}$. In contrast, at 5-6 mg/L DO, only 38\% degradation occurred. When the concentration of DO further increased from 9 to $12 \mathrm{mg} / \mathrm{l}$, no pronounced effect on the removal efficiency was observed. Results were confirmed by COD and HPLC analysis. Moreover, during treatment, no significant effect of $\mathrm{pH}$ change was observed and the $\mathrm{pH}$ remains between 7.3 and 8.8. The findings suggest that IES-Ps-1 strain could effectively be used for the removal of pesticide waste.
\end{abstract}

Keywords: Cypermethrin, Pseudomonas, degradation, agitation, wastewater, biosimulator, dissolved oxygen, pesticide waste.

\section{Introduction}

In Pakistan, insecticides, particularly Cypermethrin, are mainly used for cotton crop protection and for forestry and public health management. The very low water solubility of Cypermethrin and relatively high lipoaffinity indicate a strong bioconcentration potential in aquatic organisms when available as solute [1,2]. 
Cypermethrin actually acts on the nervous system and is toxic to bees, other beneficial insects, earthworms, fish and shrimps [3].

In the country to meet the need of food requirements for a growing population, farmers are using higher amounts of fertilizers and pesticides but at the expense of the environment and health. At present, besides pesticide contamination from agricultural fields, the agricultural industries are also contributing relatively high quantities of toxic pesticides into the environment, since most of them have either no treatment facilities or have grossly inadequate arrangements. The Karachi coastal region has become the dumping ground of hazardous waste, receiving huge quantities of untreated domestic, industrial and agricultural wastes. An effective pesticide waste treatment technology is therefore needed to prevent water pollution and to comply with increasing regulatory pressures.

Recently, bioremediation has been proven to be a suitable method for the treatment of polluted aquifers containing hazardous waste that could be implemented either in situ or off-site in specially designed reactors or wastewater treatment plants [4-6]. Moreover, in most cases, the most cost-effective and environmentally friendly treatment method has been found. Therefore, the present study describes the use of potential microorganisms and the optimum conditions that support the growth and biodegradation of pesticides in an aquatic environment using a biological treatment system. Such studies would be a valuable addition in the improvement in the design and operation of a biomechanical treatment system used for the degradation of toxic compounds like pesticides which are resistant otherwise to conventional treatment.

\section{Materials and methods}

\subsection{Pesticide, medium and culture used}

The pesticide used in this study belongs to the class pyrethroid and is commercially available as Cypermethrin. Due to low water solubility, stock aqueous solution of Cypermethrin $(1 \mathrm{mg} / \mathrm{ml})$ was prepared in sterile HPLC grade methanol (Merck).

Nutrient broth media having a composition of Beef extract 3.0gm and Pancreatic digest of gelatin 5gm, and a nutrient agar media containing additional $20.0 \mathrm{gm}$ Agar, were prepared according to the manufacturer's instruction ( $8 \mathrm{gm}$ in $1000 \mathrm{ml}$ purified water, $\mathrm{pH} 7.2$ and autoclaved at $121^{\circ} \mathrm{C}, 15$ psi for 30 minutes). The medium was used for growth and biodegradation studies.

The bacterial culture (IES- $P s-1)$ capable of degrading malathion was isolated by Hashmi [7] from agricultural soil using an enrichment technique and was used in the present study. Cypermethrin degrading culture was obtained through acclimatizing IES-PS-1 strain with gradually increased concentrations of Cypermethrin from 10 to $100 \mathrm{mg} / \mathrm{L}$ in the nutrient medium. Adapted IES-Ps-1 was stored at $4^{\circ} \mathrm{C}$ on slopes of nutrient agar containing $0.1 \mathrm{mg} / \mathrm{L}$ Cypermethrin and subcultured after every three months. 
When a new batch of tests was performed with different doses of Cypermethrin, the stock culture was first subcultured into $10 \mathrm{ml}$ nutrient broth, aerobically grown and subsequently utilized for characterization, growth and biodegradation studies.

\subsection{Characterization and growth of IES-Ps-1}

Characterization of IES-Ps-1 was performed using morphological, cultural and biochemical tests using methods described by Colins and Lyne [8] up to the stage of genus. Growth of IES-Ps-1 in a biosimulator was determined by viable cell enumeration immediately after inocculation and at 24, 48, 72, $96 \mathrm{~h}$ later. The Miles and Misra technique was used for the bacterial growth study.

\subsection{Cypermethrin degradation studies using biosimulator (activated sludge)}

The compact bench scale biosimulator (Model MF-114) consists of a stainless steel reactor with a heavy wall glass jar of borosilicate glass equipped for monitoring and controlling the rate of agitation and aeration was used.

The effect of dissolved oxygen concentrations $(6 \mathrm{mg} / \mathrm{L}, 8 \mathrm{mg} / \mathrm{L}$ and $10 \mathrm{mg} / \mathrm{L})$ on the performance of IES-Ps-1 for Cypermethrin $(80 \mathrm{mg} / \mathrm{L})$ biodegradation was evaluated. Approximately 8.5 liters of wastewater sample, inoculated with 350 $\mathrm{ml}$ culture and an appropriate quantity of Cypermethrin, was transferred into the biosimulator. The sample was strongly agitated by an impeller with flat stirring paddles and by four vertical baffles. The required temperature was maintained by the built-in thermostat and the DO concentration was achieved by diffused aeration using a pressure pump and mechanical aeration regulated through continuous agitation.

\subsection{Analytical procedure}

The sample from the biosimulator was withdrawn at timed intervals of $8,24,32$, 48 hours and analyzed for $\mathrm{pH}$, temperature, dissolved oxygen and COD as per standard procedures laid down in APHA [9].

\subsection{Extraction of Cypermethrin for HPLC analysis}

Samples were collected from the biosimulator as per the schedule and were extracted two times with $\mathrm{n}$-hexane $(75 \mathrm{ml}$ and $50 \mathrm{ml})$ by vigorous shaking for 15-20 minutes in a separatory funnel. The hexane layer was separated and evaporated to dryness at $70^{\circ} \mathrm{C}$ using a vacuum rotary evaporator (BUCHI Rotavapor R-200/205). The dried residue was then dissolved in $10 \mathrm{ml} \mathrm{HPLC}$ grade methanol. After gently vortexing and filtering through a $0.2 \mu \mathrm{m}$ membrane filter, an aliquot of $20 \mu \mathrm{L}$, was used for HPLC analysis. Each sample was injected 3 times and the mean was calculated. 


\subsection{High Pressure Liquid Chromatography (HPLC)}

The HPLC (Shimadzu, Japan) chromatographic system consisted of a solvent delivery pump LC-10 AS, connected with an autoinjector model SIL-6A and a rheodyne injection valve fitted with a sample loop $(20 \mu \mathrm{l})$. The chromatographic separation was achieved on a reverse phase $\mathrm{C} 18$ column with a guard column and monitored by UV-detection (visible spectrophotometer detector SPD-10A) set at $220 \mathrm{~nm}$. The output of the detector was connected to a chromatopack (CR6A). The mobile phase consisted of methanol (Merck HPLC grade) since Cypermethrin is miscible in alcohol. The filtered methanol was degassed prior to use by sonication. The flow rate was adjusted at $2 \mathrm{ml} /$ minute with a total elution time of 10 minutes for each run. The column was flushed with deionized distilled water and methanol whenever required to remove impurities and was allowed to equilibrate between runs.

\section{Results and discussion}

\subsection{Characterization and adaptation of bacterial isolate}

On the basis of morphological, cultural and biochemical characteristics, the bacterial isolate was identified as a member of the genus Pseudomonas according to "Bergey's Manual of Systematic Bacteriology" [10]. Characterization studies of the isolate from experimental results, as well as of those by other researchers, indicate that bacteria belonging to the genus Pseudomonas are gram-negative, rod-shaped, highly oxidative and metabolically versatile, able to degrade aromatic hydrocarbons, oil, petroleum products and pesticides [11-15].

During adaptation, it was observed that in the presence of high concentrations of Cypermethrin, the bacteria was greatly stressed and its growth was slowed as a consequence. Further, the bacteria changed its normally rod-shaped morphology to that of a coccus. However, this change was temporary, because the cells recovered the original rod form after a few days.

\subsection{Bacterial growth in biosimulator}

The results as shown in figure 1 clearly indicate that Cypermethrin had a pronounced effect in promoting better growth of IES-PS-1. In the presence of Cypermethrin the bacteria grow fast and a higher number of cells were observed when compared with the control (without Cypermethrin). The maximum count at 24 hours with $40 \mathrm{mg} / \mathrm{L}$ Cypermethrin was $13 \pm 1.73 \times 10^{7} \mathrm{CFU} / \mathrm{ml}$ and with $80 \mathrm{mg} / \mathrm{L}$, it was $19 \pm 2.65 \times 10^{7} \mathrm{CFU} / \mathrm{ml}$. However, the generation time at these concentrations ( 40 and $80 \mathrm{mg} / \mathrm{L}$ ) were noted to be 57 and 53 minutes, respectively. On the other hand in the control experiments, the cell count at 24 hours was relatively low $\left(7 \pm 1.73 \times 10^{7} \mathrm{CFU} / \mathrm{ml}\right)$ with a marked increase in generation time (98 minutes). It was further noted that the growth at $40 \mathrm{mg} / \mathrm{L}$ Cypermethrin dose significantly increased after 48 hours incubation. But the growth at $80 \mathrm{mg} / \mathrm{L}$ dose was slightly less but continued to grow until 96 hours 
incubation and a count of $7 \times 10^{7} \mathrm{CFU} / \mathrm{ml}$ was observed. This may be due to the availability of nutrients and favorable environmental conditions in the biosimulator which allows the cells to survive for 96 hours. In contrast, the population density in the control experiment (no pesticide) was comparatively less $\left(0.1 \times 10^{7} \mathrm{CFU} / \mathrm{ml}\right)$. This may be because of the presence of limited concentrations of nutrient in the wastewater sample (no Cypermethrin), which does not allow the cells to grow to higher numbers.

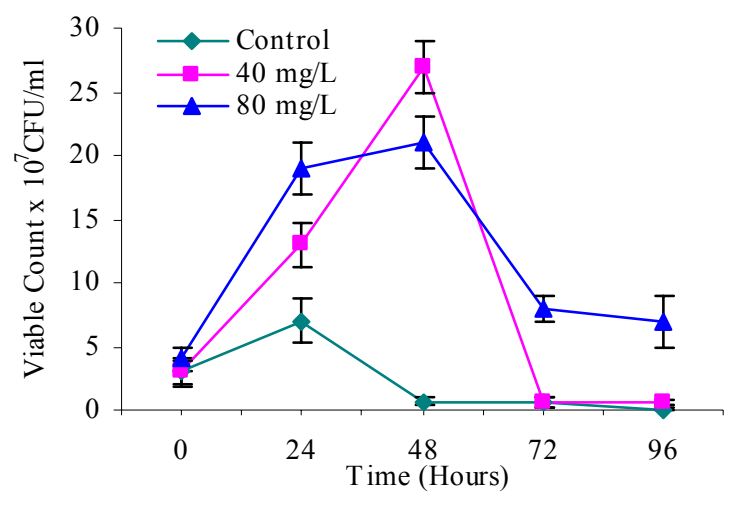

Figure 1: Growth of bacteria in the biosimulator containing Cypermethrin.

Since 78-88\% degradation of Cypermethrin observed after 48 hours of aerobic treatment in the biosimulator, it appears that biodegradation actually occurrs by the acclimated culture of IES- $P S-1$ in wastewater samples. The bacterial cells in the log phase during the period of biodegradation indicate that substrate conversion would be at its maximum as also described by Gray [16] and similarly observed in this study.

\subsection{Influence of physicochemical conditions on biodegradation performance at different dissolved oxygen}

\subsection{1 pH}

Results as shown Table 2 indicate that $\mathrm{pH}$ during treatment remained towards the alkaline side, between the range of $\mathrm{pH} 7.3$ and 8.2. Walker and Kieth [17] reported that under normal environmental temperature and $\mathrm{pH}, \mathrm{Cypermethrin} \mathrm{is}$ stable to hydrolysis with a half-life of $>50$ days. Therefore, the alkaline $\mathrm{pH}$ values which were achieved during treatment may provided an additional help in removing Cypermethrin from the biosimulator.

\subsubsection{Temperature}

During biodegradation, direct correlation was found between temperature and microbial activity. Significant removal of Cypermethrin was observed at $8-9 \mathrm{mg} / \mathrm{L}$ DO when the biosimulator temperature operated between 28 and $30^{\circ} \mathrm{C}$. However, at ambient temperature $\left(23-26^{\circ} \mathrm{C}\right)$ using a similar concentration of DO, moderate degradation occurred. The comparative results are shown in Table 2. 
The present findings have demonstrated good agreement with previous work on pesticide degradation by Pseudomonas strain in liquid culture systems and bioremediation studies in soil or natural water matrices. Karpouzas and Walker [18] reported that Ethoprophos degradation by Pseudomonas putida strain was most rapid at temperatures of 25 and $37^{\circ} \mathrm{C}$. However, at $5^{\circ} \mathrm{C}$ the strain was capable of degrading the pesticide but at a slower rate. In contrast, the dissipation was markedly reduced when culture were incubated at $42^{\circ} \mathrm{C}$. Similarly, Chaterjee et al [19] found that the optimum temperature for degradation of 2,4,5-T in soil by Pseudomonas cepacia was $30^{\circ} \mathrm{C}$, which was also the optimum temperature for its growth in liquid media.

Table 1: $\quad$ Effect of dissolved oxygen on the performance of IES-Ps-1 for Cypermethrin $(40 \mathrm{mg} / \mathrm{L})$ degradation after 48 hours.

\begin{tabular}{|c|c|c|c|}
\hline $\begin{array}{c}\text { Dissolved Oxygen } \\
(\mathrm{mg} / \mathrm{L})\end{array}$ & $\mathrm{pH}$ & $\begin{array}{c}\text { COD } \\
(\% \text { removal })\end{array}$ & $\begin{array}{c}\text { Cypermethrin } \\
(\% \text { degradation })\end{array}$ \\
\hline $\begin{array}{c}8-9 \mathrm{mg} / \mathrm{L} \\
\text { (Diffused Aeration at } \\
\text { ambient temperature) }\end{array}$ & 8.1 & 62 & 58 \\
\hline $\begin{array}{c}8-9 \mathrm{mg} / \mathrm{L} \\
\text { (Mechanical Aeration at } \\
\text { ambient temperature) }\end{array}$ & 8.3 & 82 & 81 \\
\hline
\end{tabular}

*Data indicate average values of three experiments.

Table 2: Comparative effect of dissolved oxygen on the performance of IES-Ps-1 for Cypermethrin $(80 \mathrm{mg} / \mathrm{L})$ degradation after 48 hours using mechanical aeration.

\begin{tabular}{|c|c|c|c|}
\hline $\begin{array}{c}\text { Dissolved Oxygen } \\
(\mathrm{mg} / \mathrm{L})\end{array}$ & $\mathrm{pH}$ & $\begin{array}{c}\text { COD } \\
(\% \text { removal })\end{array}$ & $\begin{array}{c}\text { Cypermethrin } \\
(\% \text { degradation })\end{array}$ \\
\hline $\begin{array}{c}5-6 \mathrm{mg} / \mathrm{L} \\
\text { Ambient Temp. } 18-25^{\circ} \mathrm{C}\end{array}$ & 7.87 & 31 & 32 \\
\hline $\begin{array}{c}8-9 \mathrm{mg} / \mathrm{L} \\
\text { Ambient Temp. } 18-25^{\circ} \mathrm{C}\end{array}$ & 7.81 & 54 & 51 \\
\hline $\begin{array}{c}8-9 \mathrm{mg} / \mathrm{L} \\
\left(30^{\circ} \mathrm{C} \text { temperature }\right)\end{array}$ & 7.33 & 89 & 78 \\
\hline $\begin{array}{c}11-12 \mathrm{mg} / \mathrm{L} \\
\text { Ambient Temp. } 18-25^{\circ} \mathrm{C}\end{array}$ & 8.20 & 83 & 88 \\
\hline
\end{tabular}

*Data indicate average values of three experiments. 


\subsubsection{Chemical oxygen demand (COD)}

It can be seen from Table 2 that at ambient temperature using $9 \mathrm{mg} / \mathrm{L} \mathrm{DO}$, the COD removal efficiency was $54 \%$ with degradation rates of $51 \%$ respectively. When DO concentration further decreased to $6 \mathrm{mg} / \mathrm{L}$, the degradation measured from COD was $31 \%$. However, at $12 \mathrm{mg} / \mathrm{L}$ DO, the COD values decreased from $7500 \mathrm{mg} / \mathrm{L}$ to $1300 \mathrm{mg} / \mathrm{L}$ (83\% degradation) and Cypermethrin degradation rate was $78 \%$ after 48 hours treatment. Results presented in Table 1 indicate both inhibition in the rates of degradation at lower DO concentration $(6 \mathrm{mg} / \mathrm{L})$ as well as at low temperature, and a good correlation was observed between COD removal and Cypermethrin degradation rates. Toprak [20] also reported similar results that COD removal during treatment was not a function of the hydraulic retention time and concomitant organic loading rate but was influenced by the influent COD concentration and temperature. However, Ahmad et al [21] reported that COD removal increased with retention time. In the present study, COD removal was found to be dependent on Cypermethrin concentration, temperature, dissolved oxygen and retention time. Moreover, it was also observed that even at high organic loading the biosimulator functioned satisfactorily when operated under controlled temperature and dissolved oxygen with a retention time of 48 hours.

\subsection{Effect of dissolved oxygen on Cypermethrin degradation using a biosimulator}

Results as shown in Table 1 indicate that although the same concentration of Cypermethrin $(40 \mathrm{mg} / \mathrm{L})$ was used in both the experiments with diffused and mechanical aeration, biodegradation efficiency were found to be significantly high at $8-9 \mathrm{mg} / \mathrm{L}$ DO using mechanical agitation. This mechanism of aeration in the biosimulator not only provided the mixing of Cypermethrin but also kept the bacteria floc suspended and therefore promoted maximum contact of bacteria with the organics they used as a food source. In contrast at $80 \mathrm{mg} / \mathrm{L}$ Cypermethrin dose using the same mechanical aeration process, at $8-9 \mathrm{mg} / \mathrm{L} \mathrm{DO}$, the biodegradation was noted to be only $51 \%$ (Table 2 ). These findings suggest that increased concentrations of Cypermethrin from $40 \mathrm{mg} / \mathrm{L}$ to $80 \mathrm{mg} / \mathrm{L}$ have a significant adverse effect on biodegradation performance. Similar effects were also observed by Toprak [20]. To confirm lower degradation at high concentrations of Cypermethrin, the DO concentration in the biosimulator was decreased down to $6 \mathrm{mg} / \mathrm{L}$. At this concentration, only $32 \%$ removal rate was observed after 48 hours treatment using mechanical aeration. These findings explain that low dissolved oxygen concencentrations and high Cypermethrin concentrations have a marked negative effect on the rate of Cypermethrin degradation. In addition, during the experiment it was also observed that water turbidity due to the presence of Cypermethrin at $80 \mathrm{mg} / \mathrm{L}$ was more than with $40 \mathrm{mg} / \mathrm{L}$ dose. This may probably decrease the oxygen transfer efficiency of aerators in the biosimulator and therefore lower the degradation rate at high concentrations. The study assumption was also supported by the literature where it is reported that treatment of hydrophobic compounds like pesticides and other toxic chemicals in aqueous systems using specialized microorganisms would 
only be possible if compounds are completely mixed by a dispersion mechanism in the reactor [22]. Therefore the mechanical aeration used during the treatment may provided the dispersion of Cypermethrin in the wastewater sample as well as maintain the favorable environmental conditions for biodegradation. Similarly several persistent organic toxic pollutants in the activated sludge process were reported to be biodegraded following the dispersion mechanism [23].

It is interesting to note that when the temperature of the biosimulator was maintained between 28 and $30^{\circ} \mathrm{C}$ using mechanical aeration $(8-9 \mathrm{mg} / \mathrm{L} \mathrm{DO})$, keeping Cypermethrin concentration constant $(80 \mathrm{mg} / \mathrm{L})$, the percentage removal was $88 \%$. When the concentration of DO further increased to $12 \mathrm{mg} / \mathrm{L}$, no further pronounced effect was observed in the rate of Cypermethrin degradation. Instead the degradation rate after the monitored time range was $78 \%$. Comparison of data reported in table 2 confirmed that microorganisms are capable of degrading the monitored substance effectively if conditions are appropriately maintained in the biosimulator. The study findings were also supported by Schlegel [24] and Palleroni [10], who reported the same optimum temperatures $\left(28-30^{\circ} \mathrm{C}\right)$ for the growth of Pseudomonas. This would mean that higher dissolved oxygen concentration $(12 \mathrm{mg} / \mathrm{L})$ did not have a pronounced effect on the rate of Cypermethrin degradation, instead $9 \mathrm{mg} / \mathrm{L}$ DO using mechanical aeration at the temperature range of $28-30^{\circ} \mathrm{C}$ proved to be stimulatory and sufficient for effective biodegradation. Zacharias et al [25] also reported that higher oxygen supply in the treatment system had no pronounced effect on the rates of biodegradation of chlorinated aromatic hydrocarbons. From the above findings, it can be concluded that the diffused aeration mechanism, low DO concentration $(6 \mathrm{mg} / \mathrm{L})$, higher Cypermethrin concentration $(>80 \mathrm{mg} / \mathrm{L})$ and temperature beyond the optimum range $\left(28-30^{\circ} \mathrm{C}\right)$ in activated sludge may have a significant adverse effect on the removal rates of organic pollutant especially for least water soluble compounds like Cypermethrin.

\section{Conclusions}

Malathion degrading bacterial isolate, IES- $P s-1$, can be used for biodegradation of pesticides wastes. However, because of the low aqueous solubility of the pesticide, slightly more difficulty was observed by IES-Ps-1 to adapt in the presence of Cypermethrin than with malathion. In the biosimulator, DO was found to be the principal governing factor in successful plant operation. Compared to diffused aeration, the mechanical aeration in the biosimulator proved to be very effective in reducing the concentration of Cypermethrin. The mechanical aeration in the biosimulator not only provided the maximum dispersion of Cypermethrin in wastewater but also maintained the sufficient dissolved oxygen required for the growth of IES- $P S-1$. Biodegradation was also found to be concentration dependent, as the increased concentration of Cypermethrin gradually decreased the treatment efficiency. However, complete removal at $20 \mathrm{mg} / \mathrm{L}$ Cypermethrin concentration would be possible if an appropriate organism (IES- $P s-1$ ) and optimum operating conditions were maintained in the biosimulator. 


\section{Acknowledgement}

We greatly acknowledge the financial support of NDP to carry out this research study.

\section{References}

[1] Sapiets, A., Swaine, H. and Tandy, M. J., Cypermethrin. In: Analytical Methods for Pesticides and Plants Growth Regulators. Zweig G., Sherma J. (eds). Academic Press, New York, XIII: 33, 1984.

[2] Kollman, W. and Segawa, R., Interim Report of the Pesticide Chemistry Database. Environmental Hazards Assessment Program. Department of Pesticide Regulation. 1995.

[3] Stepheson, R.R., Aquatic toxicology of Cypermethrin. In: Acute toxicity to some freshwater fish and invertibrates in laboratory tests. Aquatic. Toxicol. 2, pp. 253-270, 1982.

[4] Bharati, J.B., Seema, S.S, Pradnya, P.K., Bioremediation of an industrial effluent containing Monocrotophos. Curr Microbiol. 45(5), pp. 346-349, 2002.

[5] Quan, X., Hanchang, S., Hong, L., Pingping, Lv., YI, Q., Enhancement of 2,4-dichlorophenol degradation in conventional activated sludge systems bioaugmented with mixed special culture, Water Research, 38(1), pp. 245253, 2004.

[6] Chen, K. F., Huang, W. Y., Kao, C. M., Yeh, T. Y. and Frank, H., Biodegradability of 2,4-dichlorophenol under different redox conditions, Practice Periodical of Hazardous, Toxic, and Radioactive Waste Management, 9(3), pp. 141-146, 2005.

[7] Hashmi, I., Microbiological transformation of hazardous waste during biological treatment. Ph.D. Thesis. Institute of Environmental Studies, University of Karachi. Pakistan. 2001.

[8] Collins, C.H. and Lyne, P.M., Microbiological Methods. $5^{\text {th }}$ Edition. Butterworth and Co (Publishers) Ltd., 1985.

[9] APHA, Standard Methods for Examination of Water and Wastewater, 19th ed., American Public Health Association, Washington, D.C. 1998.

[10] Palleroni, N.J., Genus I Pseudomonaceae Winslow, Broadhurst, Buchanan, Krumwiede, Rogers and Smith 1917, 555 ${ }^{\mathrm{AL}}$. In Bergey's Manual of systematic Bacteriology, Vol.1, ed. Sneath. P.H.A. Williams and Wilkins, Baltimore, Md. pp. 140-199. 1986.

[11] Martin, M., Mengs, G., Plaza, E., Garbi, C., Sanchez, M., Gibello, A., Gutierrez, F. and Ferrer, E., Propachlor removal by Pseudomonas strain GCH 1 in an immobilized cell system. Appl Environ Microbiol. 66(3), pp. 1190-1194, 2000.

[12] Ramanathan, M. P. and Lailithakumari, D., Complete mineralization of methyl parathion by Pseudomonas sp. $\mathrm{A}_{3}$, Appl Biochem Biotechno,80(1), pp. 1-12, 1999. 
[13] Lee, S.G., Yoon, B.D., Park, Y.H. and Oh, H.M., Isolation of a novel pentacholorophenol-degrading bacterium, Pseudomonas sp. Bu 34. Journal of Applied Microbiology. 85, pp. 1-8, 1998.

[14] Ramos, T.L., Duque, E., Huertas, M.J. and Haidour, A., Isolation and expansion of the catabolic potential of a Pseudomonas putida strain able to grow in the presence of high concentration of aromatic hydrocarbons. Journal of Bacteriology, 177, pp. 3911-3916, 1995.

[15] Maloney, S.E., Maule, A. and Smith, A.R.W., Microbial transformation of the pyrethroid insecticides. Permethrin, Deltamethrin, Fastac, Fenvalerate and Fluvalinate, Applied and Environmental Microbiology, 54 (11), pp. 2874-2876, 1988.

[16] Gray, N.F., The effect of small changes in incubation temperature on the five day biochemical oxygen demand test. Environmental Technology Letters, 10, pp. 253-258, 1989.

[17] Walker, M.H. and Keith, L. H., EPA's Pesticide Fact Sheet Database, Lewis Publisher, Chelsea, MI. 1992.

[18] Karpouzas, D.G. and Walker, A., Factors influencing the ability of Pseudomonas putida strains ep I and II to degrade the organophosphate ethoprophos, Journal of Applied Microbiology, 89(1), pp. 40-48, 2000.

[19] Chaterjee, D.K., Kilbane, J.J. and Chakrabarty, A.M., Biodegradation of 2,4,5-trichlorophenoxy acetic acid in soil by a pure culture of Pseudomonas cepacia. Applied and Environmental Microbiology. 44, pp. 514-516, 1982.

[20] Toprak, H., Removal of soluble chemical oxygen demand from domestic waste waters in a laboratory scale anaerobic waste stabilization ponds. Water Research, 29(3), pp. 923-932, 1995.

[21] Ahmad, K., Aziz, J.A., Tariq, M.N. and Malik, A.M., A laboratory study of the performance of anaerobic waste stabilization ponds. Sci. Tech. and Develop. 7(4), pp. 15-22. 1988.

[22] Schnoor, L.J., Fate of pesticides and chemicals in the environment. The University of Iowa, Iowa City, Iowa. Wiley-Inter Science Publication. John Wiley and Sons Inc. New York, 1992.

[23] Hannah, S.A., Austern, B.M., Eralp, A.E. and Dobbs, R.A., Removal of organic toxic pollutants by trickling filters and activated sludge. J. Water Pollution Control Fed. 60, pp.1281-1283, 1988.

[24] Schlegel, H.G., Allgemeine Mikrobiologie. Thieme, Stuttgart. In: Biological treatment of sewage by the activated sludge process. Hanel, K. Ellis Horwood, Chichester, Wiley, New York, 1969.

[25] Zacharias, B., Lang, E. and Hanert, H.H., Biodegradation of chlorinated aromatic hydrocarbons in slow sand filters simulating conditions in contaminated soil - Pilot study for situ cleaning of an individual site. Water Research, 29(7), pp. 1663-1671, 1995. 